\title{
A BOTÂNICA NA ESCOLA: APRESENTANDO POSSIBILIDADES DE TRABALHO COM ALUNOS CEGOS E VISUAIS E APROXIMANDO A UNIVERSIDADE DA ESCOLA DE EDUCAÇÃO BÁSICA ${ }^{1}$
}

\author{
Julio Cesar Bresolin Marinho², Fernanda de Lima Pinheiro³, Carla Rosangela
}

Bairros Alves ${ }^{3}$, Vera Beatriz Borgmann Reppetto ${ }^{3}$, Brasília Castelhano Soares ${ }^{3}$, Suélem Martins Figueiredo ${ }^{3}$, Cássia Viviane dos Santos Gallarreta ${ }^{4}$

${ }^{1}$ Aceito para Publicação no $2^{\circ}$ Semestre de 2016

2Professor do Curso de Ciências da Natureza na Universidade Federal do

Pampa- UNIPAMPA; juliomarinho@unipampa.edu.br.

3Universidade Federal do Pampa- UNIPAMPA.

${ }^{4}$ Governo do Estado do Rio Grande do Sul- SEDUC;

cv_gallarreta@hotmail.com.

\section{Resumo}

O ensino de Botânica na Educação Básica pode ser muito complexo e estranho aos alunos, pois contém inúmeros conceitos que podem ser de difícil compreensão. Visando facilitar o ensino e aprendizagem de Botânica foi desenvolvido, com alunos do terceiro ano do Ensino Médio, o projeto de extensão "Ações educativas de Botânica: uma forma de complexificar o conhecimento sobre os vegetais e aproximar Universidade-Escola". Tal projeto visa, não apenas complexificar o ensino dos vegetais, como também estreitar os laços entre a universidade e a escola, este objetivo tornou-se necessário ao constatarmos durante o reconhecimento escolar, que os alunos tinham pouco conhecimento que existia uma universidade federal na cidade. No decorrer do projeto, descobrimos formas de incluir os alunos cegos da escola, criando modelos palpáveis acerca dos conteúdos estudados, tendo em vista que os mesmos não tinham maneiras de enxergar o que era mostrado no livro didático, no quadro ou até mesmo nas saídas de campo. Os modelos incluíram estes alunos cegos e ajudaram os demais na aprendizagem dos conteúdos. $O$ projeto tem, de forma direta e indireta, modificado a vida destes estudantes, seja em uma aula prática ou no convívio cotidiano com os colegas. As turmas 
participantes estão muito mais unidas, ajudam uns aos outros e estão mais entrosadas em aula, assim como também mostram mais interesse pela parte do estudo de Botânica. Além disso, hoje estes alunos cogitam a possibilidade de ingressar no Ensino Superior, realidade esta que estava muito distante deles quando iniciamos as atividades.

Palavras-chave: Botânica; Ensino de Ciências; inclusão.

\section{Introdução}

O ensino das temáticas relacionadas com o estudo dos vegetais na Educação Básica, por muitas vezes, é tratado de forma exclusivamente diretiva (BECKER, 2001), conceitual e carecendo de significado e sentido para os estudantes. Com tal constatação, elaboramos e desenvolvemos o projeto de extensão "Ações educativas de Botânica: uma forma de complexificar o conhecimento sobre os vegetais e aproximar Universidade-Escola", o qual está registrado sob o no 10.029/15 no Sistema de Informação de Projetos de Pesquisa, Ensino e Extensão da Universidade Federal do Pampa (SIPPE UNIPAMPA).

Com a execução do referido projeto, buscamos desenvolver diversas ações relacionadas com o ensino e a aprendizagem de Botânica. Nesse trabalho, nos propomos a apresentar as atividades desenvolvidas, bem como analisar e discutir os resultados obtidos com o desenvolvimento do projeto.

\section{O projeto e o meio onde está inserido}

As atividades foram desenvolvidas com alunos do Ensino Médio de Uruguaiana, RS da Escola Estadual Marechal Cândido Rondon, a qual é parceira da Universidade Federal do Pampa - UNIPAMPA, Campus Uruguaiana, pois conta com a presença de bolsistas do PIBID (Programa Institucional de Bolsas de Iniciação à Docência) - Subprojeto Ciências da Natureza. As ações que foram desenvolvidas nessa escola com esses alunos foram pensadas para que o ensino dos vegetais se torne mais atraente, significativo e com sentido para esses sujeitos.

Tal projeto surge baseado nas dificuldades de se trabalhar os conteúdos de Botânica na Educação Básica (SILVA; CAVALLET; ALQUINI, 2005; SILVA; SARAIVA; REZENDE, 2013; GHILARDI-LOPES, 2014), portanto alguns 
objetivos o norteiam como: contextualizar o ensino de Botânica por meio de Temas Geradores, assim como apresentar mais significado para o estudo dos vegetais, desenvolver atividades práticas e saídas de campo para auxiliar na compreensão de conceitos e ainda trabalhar com aulas interdisciplinares trazendo elementos de outras áreas do conhecimento, como as Linguagens, para complexificar os saberes de Botânica. Mas algo que objetivamos também é a aproximação da comunidade com a Universidade ${ }^{1}$, pois ao realizar 0 reconhecimento da escola com alunos e professores, sentimos que estas duas realidades estavam distantes uma da outra.

\section{Detalhamento das atividades}

Foram realizadas várias oficinas de desenho acerca do tema proposto pelo projeto de extensão, a ideia do desenho criou um espaço para que pudesse ser trabalhada a interdisciplinaridade com a área das Linguagens (componente curricular - Educação Artística) tendo em vista que os alunos, além de identificar as partes dos vegetais (objetos de estudo), deveriam esboçar desenhos com uma base artística. Desta forma, a professora de Educação Artística da escola, também se envolveu no projeto, avaliando o desempenho artístico dos alunos e técnicas adotadas para compor seus desenhos. As oficinas têm sido desenvolvidas com cerca de 60 alunos da escola em que o projeto está sendo desenvolvido.

Agora iremos relatar algumas das oficinas realizadas no primeiro semestre de 2015:

\section{Oficina sobre flor}

Durante o planejamento as bolsistas ID (Iniciação à Docência) julgaram pertinente fazer modelos em biscuit ${ }^{2}$ (Figura 1) para melhor aproveitamento da aula tanto para os alunos cegos ${ }^{3}$ quanto para os alunos que enxergam, pois as

\footnotetext{
1 Traçamos esse objetivo, pois a UNIPAMPA é uma instituição relativamente jovem na região. Desse modo, ainda não é conhecida por boa parte da população local.

2 Biscuit é uma massa usada para criar diversas peças e também é conhecida como porcelana fria, devido ao fato de não precisar ir ao forno e sua secagem ser ao ar livre. Pode ser facilmente colorida com tinta de qualquer cor, fácil de moldar e, após secar, fica rígida e resistente. Disponível em: <http://www.o-que-e.com/o-que-e-biscuit/>.

${ }^{3} \mathrm{~A}$ escola em questão possui inúmeros alunos cegos e outros com diversas necessidades físicas especiais. Participaram deste projeto um menino e uma menina cegos, assim como uma
} 
flores disponíveis próximas da escola eram muito frágeis e poderiam facilmente perder suas características ao serem manuseadas. Os modelos foram construídos com diferentes formas, texturas e cores, sendo o mais fiel possível aos modelos reais.

Figura 1: Confeccionando as flores em biscuit

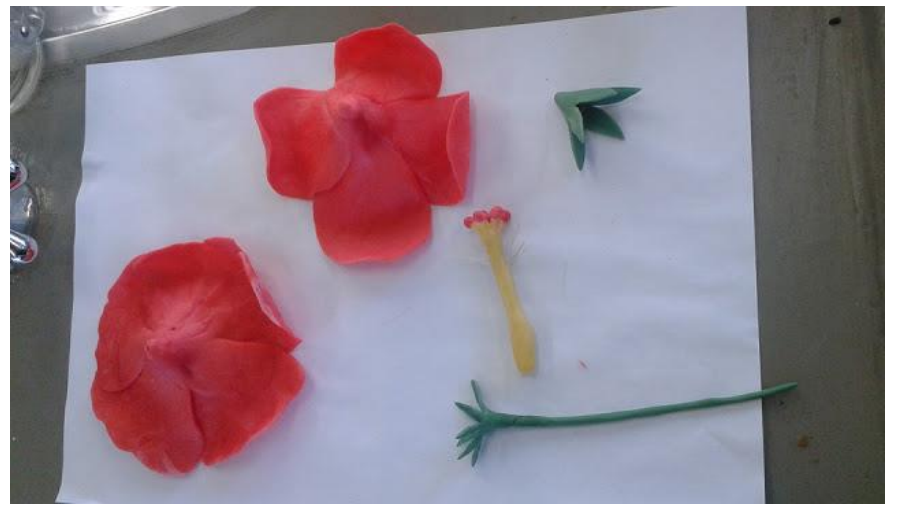

Fonte: Arquivo dos autores

A atividade iniciou com uma saída aos arredores da escola para que os alunos pudessem observar e coletar flores, assim eles puderam visualizar o meio em que sua flor escolhida estava inserida, os alunos cegos foram conduzidos pelos colegas de forma que pudessem tocar na árvore e nas flores antes de escolherem seus exemplares. Após, a turma foi conduzida ao laboratório de Ciências da escola onde a professora regente da classe fez uma explicação sobre as partes da flore. Os alunos visuais acompanharam visualizando a explicação da professora e os alunos cegos receberam uma atenção especial das bolsistas ID que iam mostrando com os modelos em biscuit as partes que a professora apontava no quadro para os alunos visuais (Figura 2). Em seguida, os alunos desenharam suas flores com total liberdade de criação, contanto que as partes fossem definidas e devidamente identificadas (Figura 3). 
Figura 2: Flor em biscuit (esquerda) e flor real (direita)

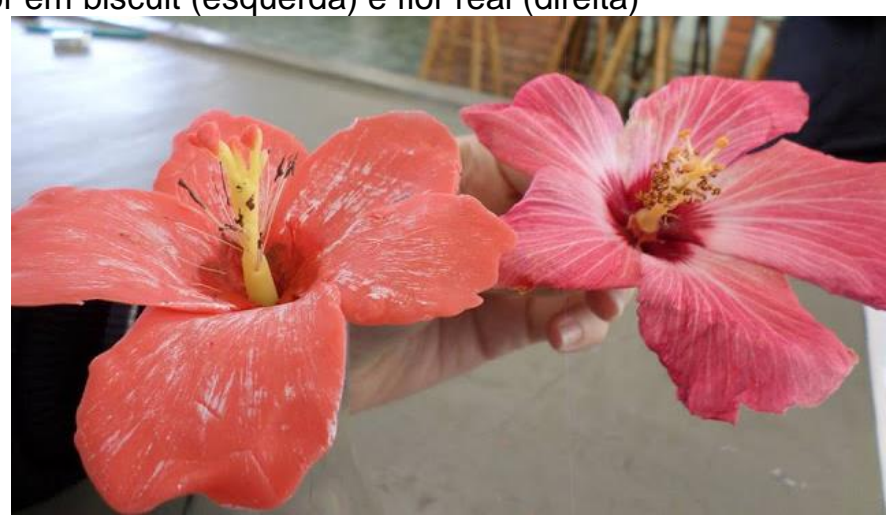

Fonte: Arquivo dos autores

Figura 3: Trabalho dos alunos ao final da aula

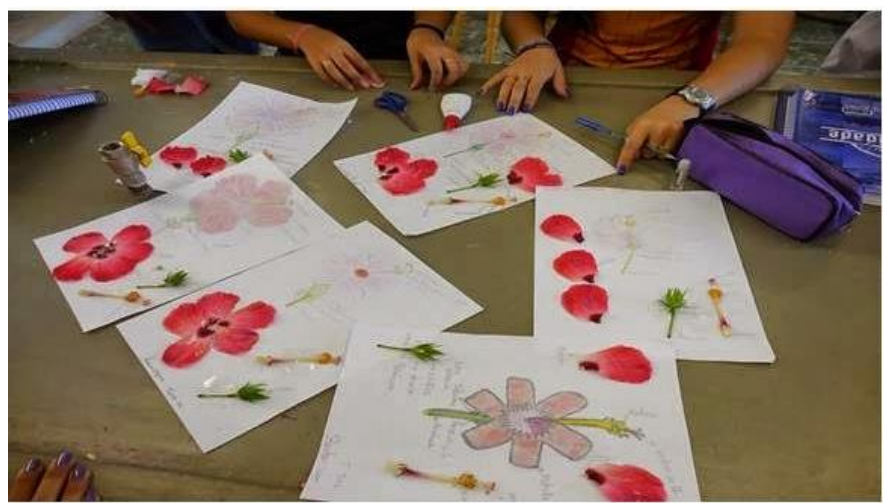

Fonte: Arquivo dos autores

\section{Oficina sobre fruto}

Para a atividade prática sobre frutos, pedimos que cada um dos alunos trouxesse de casa uma fruta que gostassem, pois não haviam árvores frutíferas na escola, nem a sua volta. Levaram então vários tipos de frutas, as mesmas foram cortadas para que os alunos pudessem enxergar o interior da fruta. Colocaram-se as frutas dispostas em bandejas nas bancadas do laboratório de Ciências, as quais foram devidamente higienizadas. A turma ouviu as explicações acerca do conteúdo e puderam visualizar na bancada os tipos de fruto, posteriormente as desenharam e identificaram suas partes. Com os alunos cegos, foi adotado outro procedimento: A professora disponibilizou luvas para eles e os mesmos puderam manusear as frutas desvendando quais eram as partes e de qual fruto se tratava (Figura 4). 
Figura 4: Aluno cego identificando as frutas através do toque

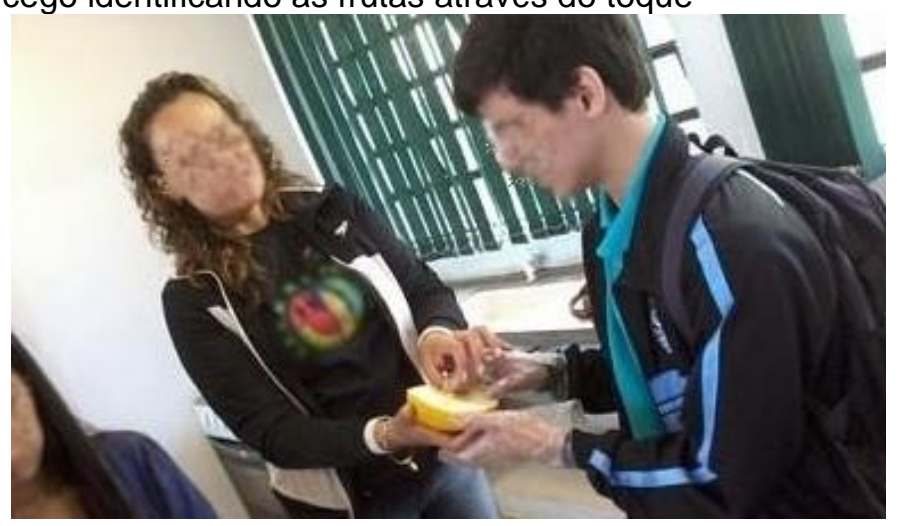

Fonte: Arquivo dos autores

Ao final da prática, as bolsistas ID foram até a cozinha da escola e prepararam uma salada de frutas com os frutos que não foram manuseados e nem abertos durante a aula. O lanche natural foi distribuído para os alunos durante o recreio.

\section{Oficina sobre semente}

Para a prática sobre semente, foram utilizados grãos de feijão trazidos pelos alunos de suas casas. A professora iniciou a aula explicando e desenhando as partes e a função de uma semente. Nesta atividade, os alunos tiveram que, além de desenhar, identificar as partes e escrever suas funções, tiveram que realizar o plantio das sementes em copos plásticos (Figuras 5 e 6). A turma ainda recebeu a missão de registrar o crescimento dos seus feijões em casa com uma câmera. Nesta atividade, os alunos cegos também realizaram o plantio e também acompanharam o crescimento de suas plantinhas através do toque. 
Figura 5: Preparando as sementes e algodão

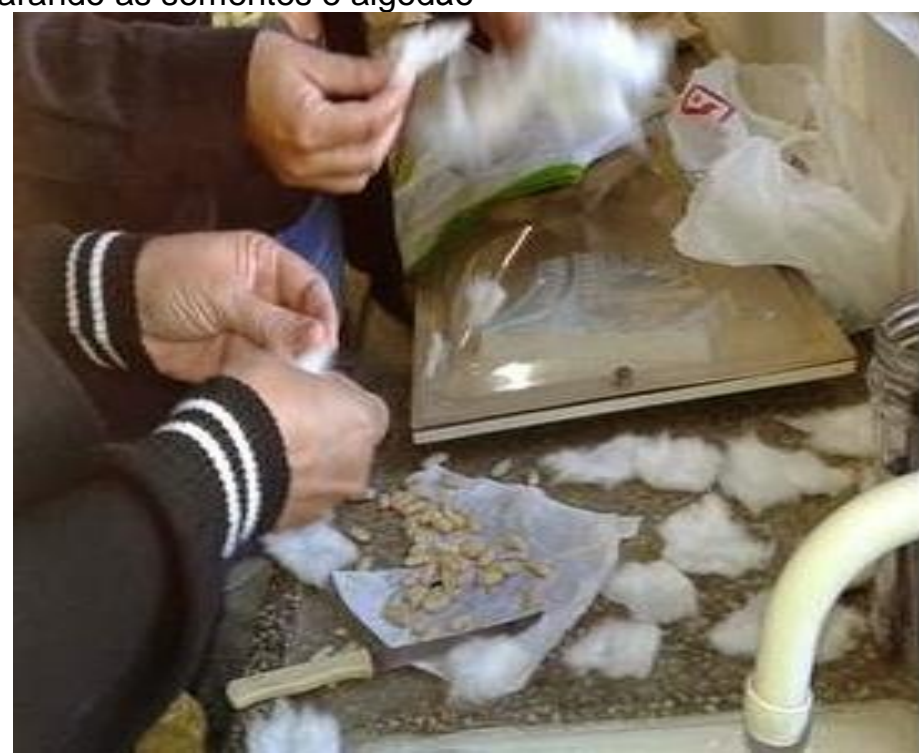

Fonte: Arquivo dos autores

Figura 6: Semente já plantada

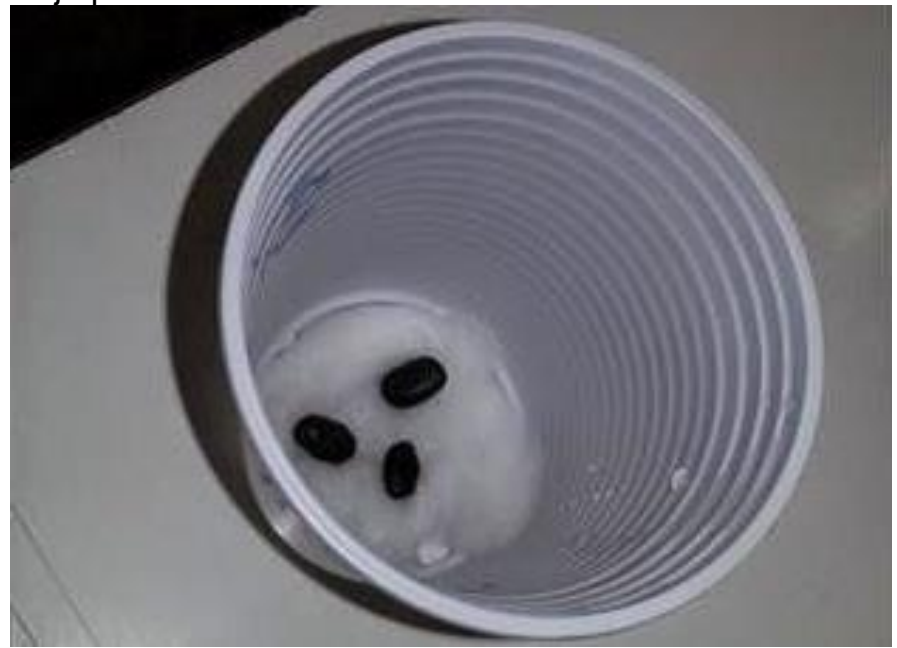

Fonte: Arquivo dos autores

\section{Oficina sobre folha}

Nesta prática, os alunos foram levados para fora da escola para coletarem suas folhas e observarem o local onde elas estavam (Figura 7), da mesma forma como fizeram na prática sobre flores. Os alunos cegos também foram para o meio externo e exploraram as folhas através do toque e guiados pelos colegas (Figura 8). Ao voltarem para escola, foram levados ao laboratório de Ciências onde a professora fez uma explicação e representação no quadro sobre as partes da folha. Em seguida, cada aluno realizou três desenhos de três folhas diferentes, utilizando três técnicas de desenho diferentes. Os alunos 
cegos exploraram vários tipos de folhas com vários tipos de texturas, identificando suas partes através do toque.

Figura 7: Alunos buscando folhas nos arredores da escola

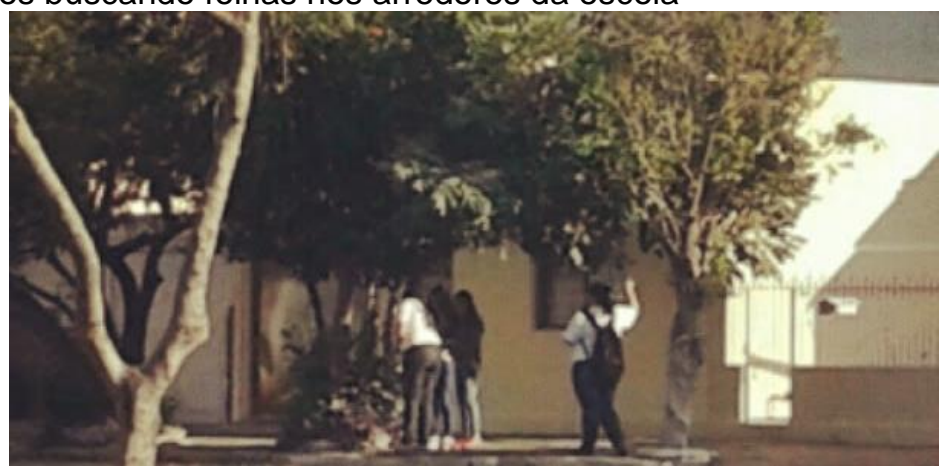

Fonte: Arquivo dos autores

Figura 8: Aluno cego sentindo a folha

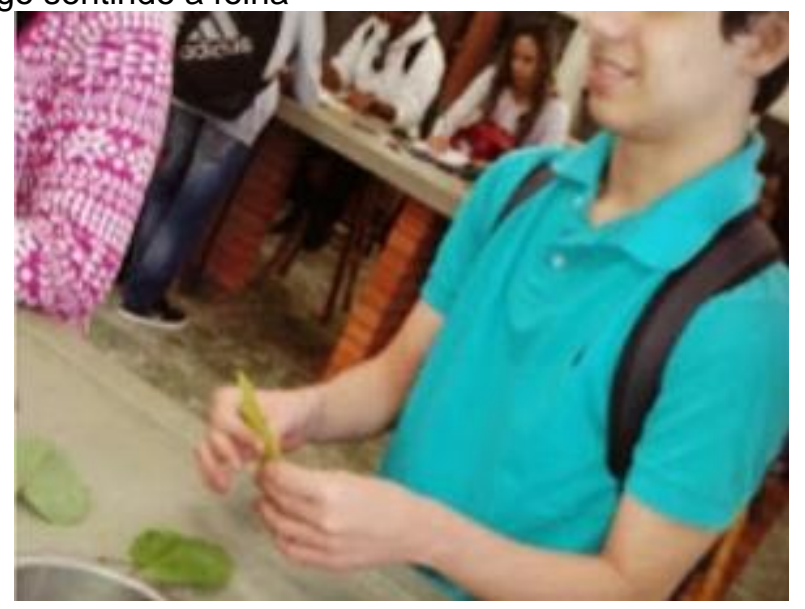

Fonte: Arquivo dos autores

\section{Oficina sobre raiz}

Na reunião de planejamento para esta prática, as bolsistas ID resolveram cultivar uma batata doce para que a mesma criasse raízes. A batata foi furada com palitos de dente e posta de molho em um copo de água, passaram-se alguns dias e ela começou a criar raízes, a água foi trocada várias vezes para que a batata não apodrecesse, após um tempo as raízes estavam visíveis e a batata pronta para a aula prática (Figura 9). Além desta raiz, as bolsistas ID ainda conseguiram outros tipos diferentes para contrastar e exemplificar um maior número de raízes. 
Figura 9: Raízes utilizadas na prática

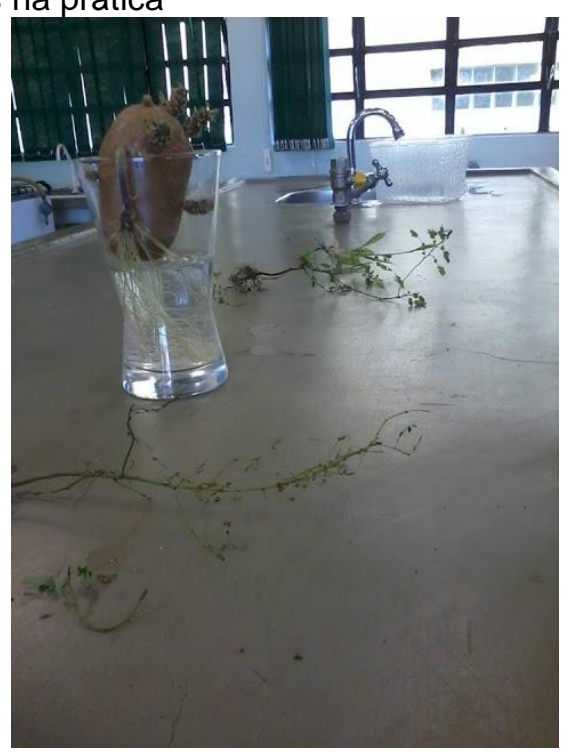

Fonte: Arquivo dos autores

A aula começou no laboratório de Ciências da escola com uma explicação da professora sobre os vários tipos de raízes, a mesma desenhou no quadro e identificou as partes. Os alunos visuais então puderam visualizar as raízes com lupas (Figura 10) e os alunos cegos exploraram as raízes através do toque e com auxílio das bolsistas ID. Após as especificações, os alunos desenharam as raízes e identificaram suas partes.

Figura 10: Aluna observando a raiz da batata com uma lupa

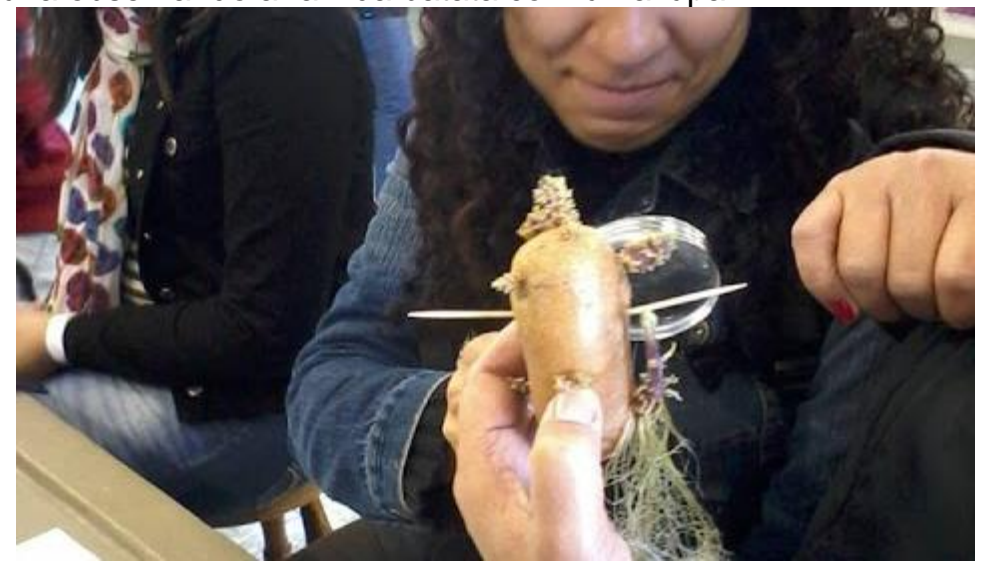

Fonte: Arquivo dos autores

\section{Oficina sobre caule}

Para a prática do caule utilizou-se um tronco de lenha com os anéis visíveis e a batata que foi cultivada para a prática da raiz, assim como alguns feijões que já estavam em estágio avançado de crescimento (Figura 11). A aula 
seguiu o mesmo roteiro, a professora levou os alunos ao laboratório de Ciências, explicou as partes do caule, suas funções e os alunos desenharam. Em seguida, a professora os ensinou a descobrir a idade de uma árvore através de seus anéis crescimento e assim os alunos cegos e visuais foram desafiados a descobrir a idade do tronco que estava em exposição na bancada, para isso eles puderam tocar/manusear e discutir entre si até que todos chegassem a um acordo de qual seria a idade da árvore.

Figura 11: Caules utilizados na prática

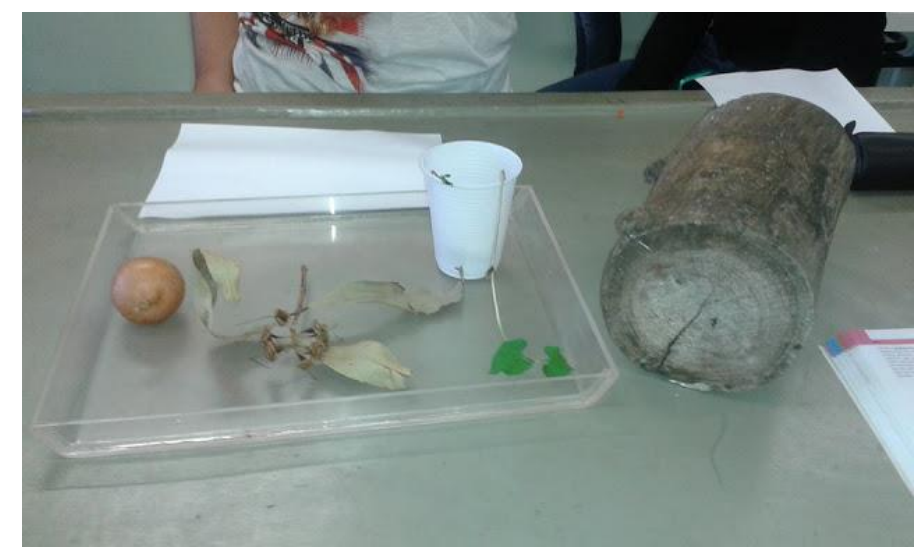

Fonte: Arquivo dos autores

\section{Oficina "Manhã dos bolos"}

Outra atividade desenvolvida com a turma foi uma manhã de bolos e chás. Nessa, cada grupo levou um bolo de raiz, caule, folha, flor, fruto e semente, e as bolsistas ID fizeram chá com ervas medicinais para acompanhar. Neste dia, os alunos foram levados ao refeitório e lá foram surpreendidos com seus desenhos expostos em varais por todos os lados. Após, cada grupo apresentou um trabalho e contou um pouco sobre seu bolo. Ao final, houve a degustação onde os funcionários da cozinha da escola foram convidados a participar.

\section{Ciclo das angiospermas}

Dando seguimento ao projeto, planejamos uma aula utilizando materiais em biscuit, pois a professora estava ensinando o ciclo das angiospermas e este estava ilustrado no livro didático. Fizemos o ciclo em diferentes cores e com riqueza de detalhes para que os alunos cegos pudessem entender o conteúdo com clareza. 
Após criarmos o ciclo semanas antes da prática ser realizada, organizamos o laboratório e chamamos as turmas para observar, tocar e colocar em ordem as peças que deixamos de forma sortida na mesa de acordo com a explicação que a professora proferiu (Figuras 12 e 13). Os alunos sentiram-se desafiados e logo realizaram a atividade, ao final consultaram o livro para ter certeza de que a ordem estava certa.

Figura 12: Alunas colocando em ordem as peças

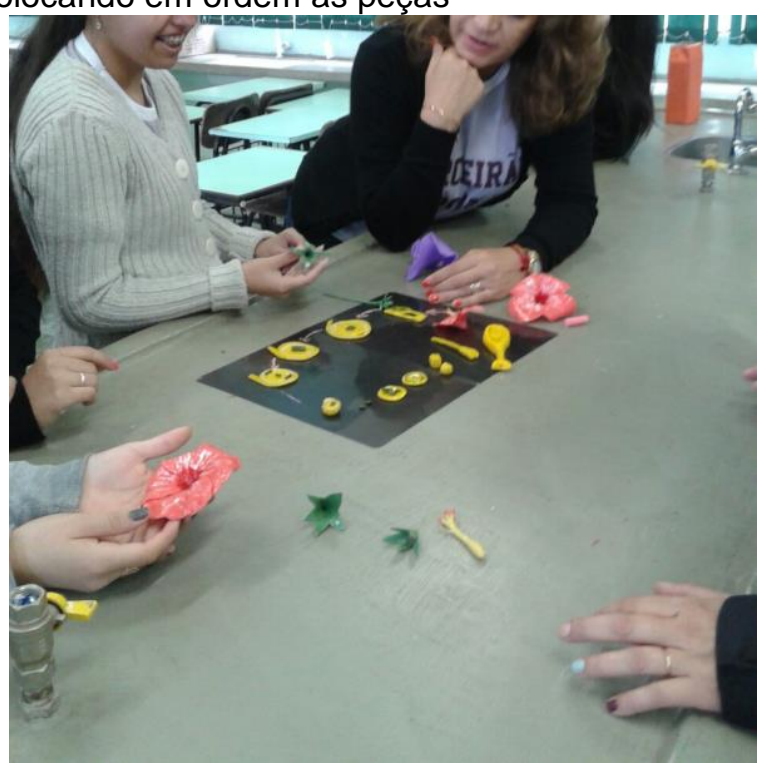

Fonte: Arquivo dos autores

Figura 13: Aluna (esquerda) ajudando a colega (direita) deficiente visual a explorar o material

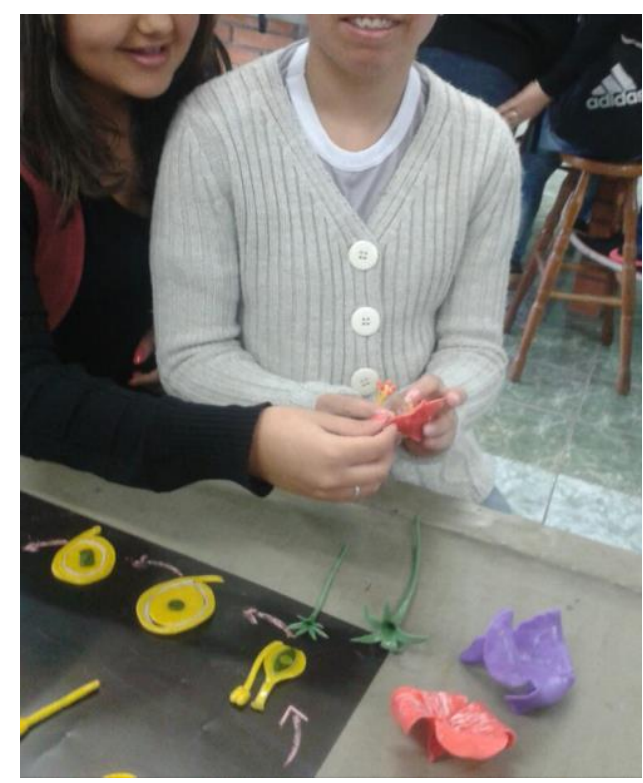

Fonte: Arquivo dos autores 


\section{Ciclo das gimnospermas (Pinho)}

Outra aula em que fizemos um ciclo em biscuit foi a do ciclo do Pinho, uma gimnosperma. O mesmo também estava ilustrado no livro e procuramos manter a mesma riqueza nos detalhes.

Seguimos o mesmo planejamento das angiospermas: Organizamos o laboratório de Ciências, chamamos as turmas, disponibilizamos os materiais adaptados nas bancadas de forma desorganizada e os mesmos foram instigados a colocar na ordem que havia sido explicada anteriormente. Novamente os alunos não encontraram dificuldade em realizar a atividade e puderam conferir no livro se haviam colocado na ordem correta.

Figura 14: Aluna cega sentindo o ciclo com o auxílio da professora e de uma bolsista ID

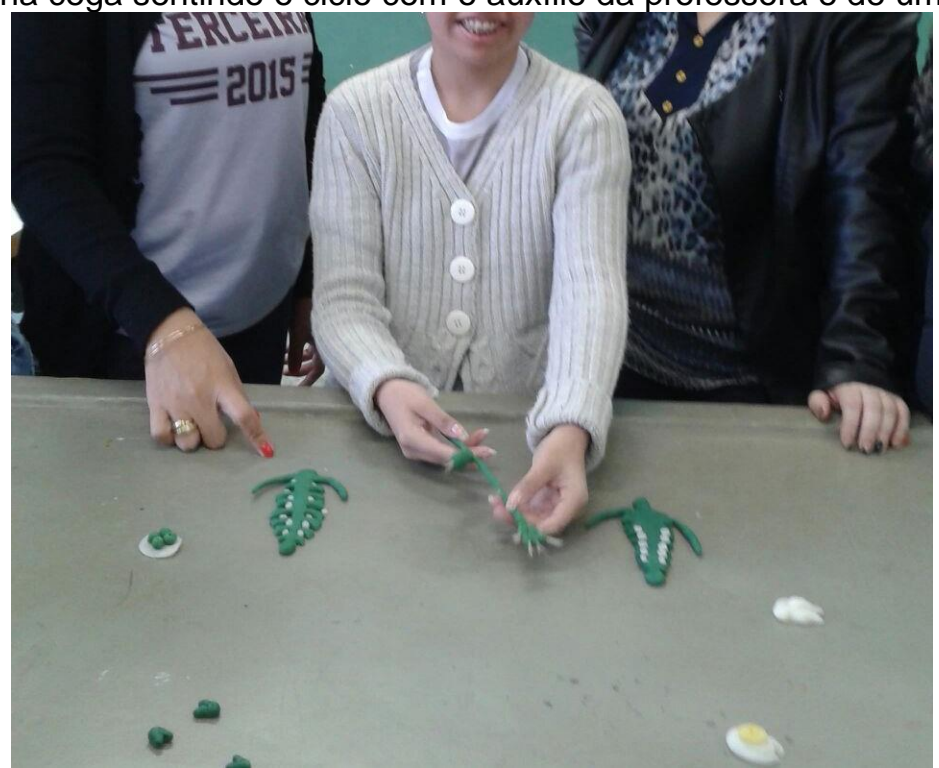

Fonte: Arquivo dos autores

\section{Análise e discussão}

Com o que já desenvolvemos do projeto na referida escola, já podemos observar uma maior participação dos alunos nas aulas práticas, significação do conteúdo expresso na apresentação dos trabalhos, solidariedade dos demais colegas para com os alunos cegos e também mais interesse pelo conteúdo de Botânica.

Evidenciamos a importância das atividades práticas desenvolvidas para a aprendizagem dos alunos. Segundo Pessin e Nascimento (2010, p. 1):

Os experimentos despertam a motivação e o interesse dos alunos pelo saber, facilitam a compreensão de fenômenos naturais e de concepções científicas [...] a aprendizagem dos conteúdos de Botânica exige atividades práticas que permitam aos alunos vivenciar 
os conteúdos teóricos previamente trabalhados de forma contextualizada.

Os alunos estando em contato com as partes dos vegetais (flores, frutos, folhas, sementes, raízes e caules), possibilita um maior significado ao aprendido e uma maior aproximação com a realidade, pois percebe coisas do seu cotidiano. A utilização de aulas práticas possibilita um maior aprofundamento do conteúdo da disciplina, pois, os alunos deixam de ser grandes depósitos do conjunto de informações transmitidas pelo professor (PESSIN; NASCIMENTO, 2010).

Em relação ao trabalho com os alunos cegos, podemos perceber que ao confeccionarmos modelos que possam ser manuseados pelos estudantes ampliamos a forma com que os mesmos entendiam o conteúdo levando em consideração o fato de que os mesmos possuem certa restrição para entender fenômenos abstratos (SANTOS; MANGA, 2009), pois normalmente são expressos em livros e em aula de forma visual. Acrescentamos não apenas na vida destes alunos, como também agregamos valor ao nosso aprendizado enquanto bolsistas de Iniciação Docência, pois a partir do momento em que nos atentamos às necessidades de tais alunos, passamos a pensar nas diversas necessidades dos demais, seja por limitações físicas ou cognitivas.

Evidenciamos que os alunos sempre pedem mais atividades relacionadas com o estudo dos vegetais e já estão animados pelas saídas de campo que estão sendo organizadas para que eles possam observar vários tipos de vegetações. O que os deixa ansiosos também é a visita à UNIPAMPA Campus Uruguaiana, na qual possui muitos vegetais para observação. Muitos alunos não sabiam que a Universidade era Federal e que isso significava que ela é gratuita, nem sabiam que a mesma possuía tantos cursos em diferentes áreas do conhecimento. Assim, o projeto além de trabalhar com as temáticas de diversidade vegetal está ajudando a aproximar estes jovens da Universidade.

\section{Considerações finais}

No decorrer deste primeiro semestre de projeto, é perceptível a mudança na comunidade escolar para com a UNIPAMPA e com a temática de Botânica. A visão que eles tinham a respeito da universidade mudou de forma 
significativa do início do projeto até aqui, hoje eles cogitam a possibilidade de ingressar no ensino superior e seguir a carreira acadêmica, realidade essa que estava muito distante no início do ano. As ações do PIBID em parceria com o projeto têm estreitado os lados entre as aulas consideradas "normais" e as aulas "diferentes". Hoje as turmas participam mais e de uma forma mais tranquila, além de mostrar mais interesse sobre a temática dos vegetais e da possibilidade do ingresso no Ensino Superior.

Facilitamos o aprendizado de Botânica, demos maior importância ao tema, instigamos e incentivamos os alunos. Acreditamos que, além da sensação de dever cumprido ao incluir toda a turma, incentivar estes estudantes e fazer deles parte da turma, nos deu maior confiança no nosso trabalho e nos fez perceber o quão importante é atentar-se às diversas necessidades dos discentes. Os alunos cegos não estão mais deslocados, fazem parte de grupinhos como qualquer outro adolescente, podem fazer trabalho em grupo sem ficar de lado, entre outras coisas. Os modelos palpáveis fizeram uma diferença muito maior do que apenas fazê-los entender o conteúdo, incluiu estes alunos no contesto social o qual foram inseridos.

É esperado que nas próximas ações do projeto, os alunos continuem mostrando interesse pelas práticas, saídas de campo e mostrem cada vez mais vontade de estarem inseridos na UNIPAMPA, num futuro não muito distante. $O$ projeto de Botânica seguirá com suas atividades até o final do ano, sempre visando o melhor entendimento dos conteúdos de Biologia articulados com outras áreas de saberes e sempre incentivando a construção pessoal dos alunos, o estudo e o ingresso no Ensino Superior.

\section{Referências}

BECKER, Fernando. Educação e construção do conhecimento. Porto Alegre: Artmed, 2001.

PESSIN, L. R.; NASCIMENTO, M. T. A importância das aulas práticas no ensino de botânica, a partir do processo de ensino e aprendizagem em aulas e atividades teórico- práticas. In: Anais do II Congresso Fluminense de Iniciação Científica e Tecnológica, 2010.

SANTOS, C. R.; MANGA, V. P. B. B. Deficiência Visual e ensino de Biologia: Pressupostos inclusivos. Revista FACEVV, n. 3, p. 13-22. jul./dez. 2009. 
SARAIVA, Izabella Scalabrini; REZENDE, Juliana de Lima Passos. Botânica sempre viva na escola: ensino superior. In: Anais do 64을 Congresso Nacional de Botânica \& XXXIII ERBOT - Encontro Regional de Botânicos MG, BA e ES. Belo Horizonte, 2013.

SILVA, Lenir Maristela; CAVALLET, Valdo José; ALQUINI, Yedo. Contribuições à reflexão sobre a concepção de Natureza no ensino de Botânica. R. bras. Est. Pedag., Brasília, v. 86, n. 231/214, p. 110-120, maio/dez. 2005.

SILVA, Juliana Nascimento; GHILARDI-LOPES, Natalia Pirani. Botânica no Ensino Fundamental: diagnósticos de dificuldades no ensino e da percepção e representação da biodiversidade vegetal por estudantes. Revista Electrónica de Enseñanza de las Ciencias, v. 13, n. 2, p. 115-136, 2014. 